\title{
RESEARCH
}

Open Access

\section{Soft drink intake is associated with weight gain, regardless of physical activity levels: the health workers cohort study}

Romina González-Morales, Francisco Canto-Osorio , Dalia Stern², Luz María Sánchez-Romero', Leticia Torres-Ibarra', Rubí Hernández-López³ , Berenice Rivera-Paredez³ , Dèsirée Vidaña-Pérez', Paula Ramírez-Palacios ${ }^{4}$, Jorge Salmerón ${ }^{3}$, Barry M. Popkin ${ }^{5}$ and Tonatiuh Barrientos-Gutiérrez ${ }^{1 *}$ (D)

\begin{abstract}
Background: While soft drink intake is positively associated with weight gain, no previous study has investigated whether leisure-time physical activity modifies this association. We estimated the association between soft drink intake and body weight, and explored if this association differed by levels of leisure-time physical activity.

Methods: We used data from the health workers cohort study, a prospective study of Mexican adults (20 to 85y old), including 1268 health workers and their families, who were assessed at baseline (2004-2006) and follow-up (2010-2012). We assessed soft drink intake (cola and flavored soda) using a validated food frequency questionnaire. We measured leisure-time physical activity using a self-report questionnaire, and categorized according to the 2010 World Health Organization (WHO) recommendations. Body weight was measured by trained personnel. The association between changes in soft drink intake and weight change, and if such association varied by levels of physical activity was estimated through fixed-effect models.

Results: An increase in one serving per day of soft drink was associated with $0.10 \mathrm{~kg}(95 \% \mathrm{Cl} 0.00,0.19)$ increase in weight per year. This association was not modified by leisure-time physical activity, as demonstrated by the magnitude of the coefficient of the interaction between soft drink, leisure-time physical activity, and time $(-0.03 \mathrm{~kg}$, $95 \% \mathrm{Cl}-0.27$ to 0.21 ); people who complied with the WHO physical activity recommendations gained $0.36 \mathrm{~kg} / \mathrm{year}$ per serving of soft drink, compared to $0.48 \mathrm{~kg} /$ year for people without sufficient physical activity.

Conclusions: Soft drink intake was associated with weight gain. Leisure-time physical activity did not modify the association between soft drink intake and weight gain. This finding challenges the idea that leisure-time physical activity is sufficient to counterbalance weight gain associated to soft drink intake.
\end{abstract}

Keywords: Soft drink intake, Weight, Physical activity

\footnotetext{
* Correspondence: tbarrientos@insp.mx

${ }^{1}$ Center for Population Health Research, National Institute of Public Health, 62100 Cuernavaca, Mor., Mexico

Full list of author information is available at the end of the article
}

(c) The Author(s). 2020 Open Access This article is licensed under a Creative Commons Attribution 4.0 International License, which permits use, sharing, adaptation, distribution and reproduction in any medium or format, as long as you give appropriate credit to the original author(s) and the source, provide a link to the Creative Commons licence, and indicate if changes were made. The images or other third party material in this article are included in the article's Creative Commons licence, unless indicated otherwise in a credit line to the material. If material is not included in the article's Creative Commons licence and your intended use is not permitted by statutory regulation or exceeds the permitted use, you will need to obtain permission directly from the copyright holder. To view a copy of this licence, visit http://creativecommons.org/licenses/by/4.0/ The Creative Commons Public Domain Dedication waiver (http://creativecommons.org/publicdomain/zero/1.0/) applies to the data made available in this article, unless otherwise stated in a credit line to the data. 


\section{Introduction}

Sugar-sweetened beverages (SSB) intake is a major modifiable risk factor for overweight and obesity. Previous meta-analyses support an association between SSB intake and weight gain [1-3], with weight gains ranging from 0.12 to $0.22 \mathrm{~kg} /$ year for every serving $(355 \mathrm{ml}$ ) consumed per day [3]. The causal pathways between SSB intake and obesity are clear, and involve an excess of calories with limited compensation, leading to overconsumption of energy $[4,5]$. This is an emergent problem for countries with high SSB intake, like Mexico. While the global annual per-capita consumption was $57 \mathrm{~L}$, in México, SSB intake was $167 \mathrm{~L}$ per person per year [6]. At the same time, the prevalence of overweight and obesity increased from $71.3 \%$ in 2012 to $75.2 \%$ in 2018 [7].

Experimental and observational studies have provided evidence of a link between SSB and obesity [8]. However, experimental studies have had short durations, ranging from 3 weeks to 6 months, providing a limited time frame for body weight change [3]. Observational studies have had longer durations, from 1 to 20 years [3]; yet, most studies have assumed that baseline SSB intake remains unchanged [2, 9-11], an assumption that could lead to biased estimates in dietary studies [12]. A subgroup of observational studies has used fixed effect models to estimate the impact of changes in intake over changes in weight, capturing longer time frames while maintaining a tight control for time invariant confounders [13]. Fixed effect estimates are scarce and have been mostly limited to high-income countries, with little information from other contexts. Having better estimates of weight change associated with changes in SSB intake from low and middle income countries is key to improve the global estimates of the impact of SSB intake on obesity [14-18].

The role of physical activity in the association between SSB intake and weight gain has been controversial and requires further analysis. Most studies that have analyzed the association between SSB intake and body weight have adjusted for physical activity, assuming that physical activity is a confounder of the association between SSB and weight (see diagram "a" from Fig. S1, available in the Additional file 1) [1, 19, 20]. However, a key point of discussion is the potential role that physical activity could play to counter the weight gain produced by SSB intake. Research funded by the SSB industry assumes that leisure-time physical activity will offset the positive energy imbalance produced by SSB intake [21, 22]. This implies that given the same level of exposure to SSB intake, people who exercise would gain less weight than those who do not exercise, making physical activity an effect modifier of the SSB and body weight association (see diagram "b" from Fig. S1, available in the Additional file 1). To our knowledge, no study has specifically tested this hypothesis. This study had two aims, first we estimated the change in body weight associated to a change in soft drink intake over 6 years, considering physical activity as a confounder. Secondly, we determined if the soft drink-weight change association was modified by leisure time physical activity. Using a prospective cohort study including adult males and females, with objective body weight measurements, we estimated the association of SSB changes in intake and body weight change, for the whole cohort, and by different levels of leisure-physical activity.

\section{Methods \\ Study design and population}

We used data from the health workers cohort study (HWCS), a longitudinal study of Mexican adults established in 2004-2006 to evaluate lifestyle characteristics and their association with chronic diseases. The source population included Mexican adult healthcare personnel and their relatives (20 to $85 y$ old) from three institutions: the Mexican Social Security Institute and the National Institute of Public Health, both located in Cuernavaca, Morelos, and the Autonomous University of the State of Mexico located in Toluca, Mexico. At baseline, 10,729 subjects were enrolled. However, due to budget restrictions, only employees from the Mexican Social Security Institute and their families $(n=2500)$ were invited to participate in the second wave of data collection (20102012), from whom 1923 answered the follow-up questionnaire $(76.9 \%$ follow-up rate within the Mexican Social Security Institute). Participants responded to selfadministered questionnaires about sociodemographic characteristics, diet, lifestyle, and medical conditions. Clinical and anthropometric measurements were obtained by trained personnel by appointments at a health clinic. Detailed information about the HWCS and the questionnaires used for data collection have been described previously.(4).

For the present analysis, we used data from the two waves. We excluded participants $<19$ years old $(n=150)$, those with missing weight $(n=156)$, soft drink intake $(n=143)$, or leisure-time physical activity $(n=5)$, pregnant women $(n=5)$, participants with implausible caloric intakes $(<600$ or $>6000 \mathrm{kcal} /$ day, $n=135$, [23] $)$ and those with missing data on covariates $(n=61)$. The final analytical sample included 1268 participants (see Fig. S2, Additional File 1).

\section{Assessment of soft drink intake}

Dietary intake was self-reported at each wave using a previously validated 116-item semi-quantitative food frequency questionnaire (FFQ) [24]. Each item asked participants to specify, on average, how often they had consumed a common unit or portion size of the food or beverage over the previous year. Ten multiple-choice 
frequencies of intake were possible: $\geq 6$ per day, $4-5$ per day, 2-3 per day, 1 per day, 5-6 per week, 2-4 per week, 1 per week, $1-3$ per month, $\leq 1$ per month, and never. The FFQ included two items on the intake of soft drink (cola and flavored sodas). Diet sodas were not included in this analysis. We converted frequency responses of soft drink to servings per day (predefined portion size of $355 \mathrm{~mL}$ ) [24].

\section{Assessment of anthropometric measures}

Trained nurses measured body weight using a calibrated electronic scale (Tanita, model BC-533) to the nearest $0.1 \mathrm{~kg}(0.1-130 \mathrm{~kg}$ range) in both waves. Participants were measured at each wave wearing minimum clothing. Trained nurses measured height with a stadiometer (Seca) to the nearest $0.1 \mathrm{~cm}$, with participants standing barefoot. Body mass index (BMI) was calculated using Quetelet's calculation [25]: weight (kilograms) divided by height (meters squared).

\section{Assessment of leisure-time physical activity}

Leisure-time physical activity was measured in both waves using a previously validated self-reported questionnaire $[26,27]$, which collected information on the frequency (days/week), time (hours/week), and intensity (light, moderate and vigorous) of 14 activities during a typical week over the last year. This questionnaire has been validated with an accelerometer in a Spanishspeaking population (Spearman correlation coefficient of 0.51 (95\% CI 0.23 to 0.71)) [27]. We calculated the number of minutes per day of leisure-time physical activity based on the self-reported amount of time (min/week) spent walking, running, cycling, jogging and playing other sports. Following the WHO guidelines, we categorized participants leisure-time physical activity as low (< $21.44 \mathrm{~min} /$ day, which is equal to $<150 \mathrm{~min} /$ week of moderate to vigorous activity), or high $(\geq 21.44 \mathrm{~min} /$ day, which is equal to $\geq 150 \mathrm{~min} /$ week of moderate to vigorous activity) [28]. We also created a continuous variable for minutes/day of leisure-time physical activity. Further, following the Physical Activities Guidelines for Americans, we categorized minutes of metabolic equivalent units (METs) of leisure-time physical activity in minutes per day as low $(<71.5 \mathrm{METs}$ minutes/day, which is equal to $<500 \mathrm{METs}$ minutes/week of moderate to vigorous activity) or high ( $\geq 71.5 \mathrm{METs}$ minutes/day, which is equal to $\geq 500$ METs minutes/week of moderate to vigorous activity).

\section{Assessment of covariates}

The 2004-2006 and 2010-2012 questionnaires, asked participants to self-report their age, sex, education, lifestyle habits such as smoking, sleeping, sedentary behaviors, alcohol intake, and any recent physician-diagnosed disease. Based on previous reports on dietary associations with weight change [15], we created nine food groups and alcohol intake using data from the FFQ. Multiple-choice frequencies of intake were converted to servings per day for food groups, (5) and grams per day for alcohol intake. We included the following food groups: red meat, vegetables, fruits, total dairy, nuts, yogurt, white bread, tortillas, and orange juice [24]. Participants self-reported the amount of time spent watching television and using a computer. These two variables were used to create a screen-time use variable in hours per week, as a proxy for sedentary behavior. Sleep duration was also self-reported as hours per day. We created a variable to identify participants with a selfreported medical diagnosis of chronic diseases that could affect soft drink intake and body weight, such as cirrhosis, diabetes, cardiovascular disease, cancer, or kidney disease. Finally, we created a time variable in years to take into consideration the time elapsed from the date of response of the first questionnaire to the date of return of the second questionnaire.

\section{Statistical analysis}

For descriptive analyses, we estimated the means and standard deviation (SD) for continuous variables and frequencies for categorical variables at baseline and followup; we also calculated the average change at the population level between baseline and follow-up. To estimate the association between soft drink intake and weight change over time, we used a fixed-effect model. This model removes all the time-invariant observed and unobserved characteristics related to soft drink intake and weight. Yet, to allow for a more flexible use of time [29], and to take into account different trajectories of weight over time, we included two-way interaction terms between: time (continuous, years) and soft drink intake (continuous, servings/day), time and sex (male/female), time and age at baseline (continuous, years) and time and leisure-time physical activity (categorical: low (< $21.44 \mathrm{~min} /$ day) and high ( $\geq 21.44 \mathrm{~min} /$ day $)$ ). Age and sex were centered at the baseline mean. In addition, we adjusted for time-varying covariates that have been previously identified as risk factors for weight gain, and that are also associated with soft drink intake: education (elementary school, secondary or high school, and college or higher), smoking (never, past, current) [30], screen time (3-4 h/week, 5-6 h/week, > $7 \mathrm{~h} /$ week) [31], sleep (continuous) [31], alcohol intake (low: $\delta 12.5 \mathrm{~g} /$ day, and high: > $12.5 \mathrm{~g} /$ day) [32], chronic diseases (yes/no), and food groups (all continuous as servings/day) (Model 1).

To test the hypothesis that leisure-time physical activity modifies the association between soft drink intake and body weight over time, we included a three-way interaction term between soft drink, time, and leisure- 
time physical activity (Model 2). This model also included two-way interaction terms for soft drink and time, soft drink and leisure-time physical activity, leisure-time physical activity and time, sex and time, and age at baseline and time. Model 2 was also adjusted for the time-varying covariates included in model 1 . In both models, we used robust standard error estimators to correct for the non-independence of participants that belonged to the same family. To aid with interpretation, we used model 2 coefficients to predict the average marginal weight change per year at pre-specified units of soft drink intake (zero, one, and two servings per day) and by levels of leisure-time physical activity. We do not present predictions for weight change for three or more servings because that group comprised only $3 \%$ of the sample. Details about the modeling strategy are included in the Additional File 2. To evaluate the goodness of fit, we used the Akaike Information Criterion (AIC) and Bayesian Information Criterion (BIC).

Finally, we conducted sensitivity analyses to evaluate the robustness of these findings. First, we replaced the dichotomous leisure-time physical activity variable for a continuous variable (minutes/day). We estimated the predicted average weight change values for pre-specified units of soft drink intake (zero, one, and two servings per day) and by percentiles of leisure-time physical activity: 1 st $(0 \mathrm{~min} /$ day $), 25$ th $(3.21 \mathrm{~min} /$ day $)$, 50th $(12.86$ $\mathrm{min} /$ day), 75 th $(31.35 \mathrm{~min} /$ day $)$ and 90 th $(60 \mathrm{~min} /$ day $)$. Secondly, we substituted the dichotomous leisure-time physical activity variable of minutes per day for METs per day. Third, to explore the potential influence of baseline weight on these results, we stratified the models by baseline BMI categories. Although physical activity in minutes per day is the most conventional measure, we used METs to have a more robust measure of time and intensity of physical activity. All analyses were performed using STATA 14.2 [33].

\section{Results}

At baseline, $74.2 \%$ of participants were women and had a mean age of 45.3 years old ( $\mathrm{SD} \pm 12.7$, range 19 to 82 yr). Average soft drink intake at baseline was 0.5 servings/day $(\mathrm{SD} \pm 0.7)$ and 0.4 servings/day $(\mathrm{SD} \pm 0.6)$ at follow-up. The average weight increased $1.1 \mathrm{~kg}$ between 2004 and 2010. Mean leisure-time physical activity ( $\mathrm{min} /$ day) was $24.10(\mathrm{SD} \pm 29.19)$ at baseline and 21.28 ( $\mathrm{SD} \pm$ 26.72) at follow-up. The prevalence of overweight and obesity increased by $4.4 \%$ from 2004 to 2010 . In addition, the prevalence of performing low levels of leisure-time physical activity also increased by $5.3 \%$ between 2004 and 2010. In the same time period, the percentage of participants in the category of $\geq 7 \mathrm{~h}$ of screentime increased from $19.2 \%$ to $24.5 \%$. The percentage of participants with chronic diseases increased from 9.4\% in 2004 to $14.8 \%$ in 2010 (Table 1).

In model 1, after adjusting for demographic, lifestyle factors, diet, and physical activity, we found that an increase in soft drink intake of 1 serving per day was associated with weight gain of $0.10 \mathrm{~kg}$ (95\% CI 0.00, 0.19) per year. In model 2, with the three-way interaction term, we found that the beta coefficient for the interaction between soft drink, physical activity and time was almost zero ( $\beta-0.03 \mathrm{~kg}$; $95 \%$ CI $-0.27,0.21)$. This suggests that the change in weight over time associated with soft drink intake does not differ by levels of physical activity. The best goodness of fit for the data was provided by the first model according to the AIC and BIC (Table 2).

Figure 1 shows the weight gain associated with soft drink intake for participants categorized "low" vs. those categorized "high" leisure-time physical activity. These are the predicted average marginal weight change estimates from model 2, that includes the non-significant triple interaction term. Among non-consumers of soft drink, people in the low physical activity category gained $0.38 \mathrm{~kg} /$ year, compared to $0.28 \mathrm{~kg} /$ year in the physically active participants $(0.10 \mathrm{~kg} /$ year difference; $95 \% \mathrm{CI}-0.05$, $0.24 \mathrm{~kg}$ ). Among people who consumed one serving of soft drink per day, those in the low physical activity category gained $0.48 \mathrm{~kg} /$ year, compared to $0.36 \mathrm{~kg} /$ year in the high physical activity category $(0.13 \mathrm{~kg} /$ year difference, $95 \%$ CI $-0.05,0.31 \mathrm{~kg}$ ). While the difference was not statistically significant, the estimate for the association of soft drink intake with weight change was smaller for individuals with higher leisure time physical activity than those with low leisure time physical activity. However, the focus of this analysis is to identify if the association between weight gain and soft drink intake varies by physical activity; contrasting the weight gain association with a one soft drink serving increase among those in the low physical activity group $(0.11 \mathrm{~kg} / \mathrm{yr})$ versus those in the high physical activity group $(0.08 \mathrm{~kg} / \mathrm{yr})$; the similarity between these two coefficients explains the lack of significance in the three-way interaction (see Table 2, model 2).

The sensitivity analyses consistently showed that, regardless of how we model leisure-time physical activity, the association between soft drink intake and weight gain persisted and was similar across levels of leisuretime physical activity. We calculated the predicted average weight change at different percentiles of physical activity and servings of soft drink, using physical activity as a continuous variable (minutes/day). The results were similar to model 2; even subjects who engaged in $60 \mathrm{~min} /$ day of physical activity gained weight, and weight gain still increased with higher levels of soft drink intake (see Table S1 and Fig. S3, available in the Additional file 2). Similar 
Table 1 Descriptive characteristics of the health workers cohort study (HWCS) sample at baseline (2004) and follow up (2010) $(N=1268)$

\begin{tabular}{|c|c|c|c|}
\hline Characteristics & $\begin{array}{l}2004 \\
\text { Mean (SD) }\end{array}$ & $\begin{array}{l}2010 \\
\text { Mean (SD) }\end{array}$ & $\begin{array}{l}\text { Average change } \\
\text { Mean difference (SD) }\end{array}$ \\
\hline Age (years) & $45.3(12.7)$ & $52.3(12.8)$ & $7.0(1.5)$ \\
\hline Soft drink intake (servings/ day) & $0.5(0.7)$ & $0.4(0.6)$ & $-0.1(0.6)$ \\
\hline Weight (Kg) & $66.9(13.1)$ & $68.0(13.7)$ & $1.1(5.7)$ \\
\hline BMI $\left(\mathrm{kg} / \mathrm{m}^{2}\right)$ & $26.5(4.3)$ & $27.1(4.5)$ & $0.6(2.2)$ \\
\hline \multicolumn{4}{|l|}{ BMI category, \% } \\
\hline$<25 \mathrm{~kg} / \mathrm{m}^{2}$ & 38.9 & 35.5 & -3.4 \\
\hline$\geq 25 \mathrm{~kg} / \mathrm{m}^{2}$ & 60.1 & 64.5 & 4.4 \\
\hline Physical activity (min/day) & $24.1(29.2)$ & $21.3(26.7)$ & $-2.8(33.6)$ \\
\hline \multicolumn{4}{|l|}{ Physical activity (min/day), \% } \\
\hline Low (<21.44 min/day) & 61.3 & 66.6 & 5.3 \\
\hline High ( $\geq 21.44$ min/day) & 38.7 & 33.4 & -5.3 \\
\hline \multicolumn{4}{|l|}{ Education, \% } \\
\hline Elementary school & 12.4 & 12.2 & -0.2 \\
\hline Secondary or high school & 37.4 & 36.7 & -0.7 \\
\hline College or higher & 50.2 & 51.1 & 0.9 \\
\hline \multicolumn{4}{|l|}{ Smoking status, \% } \\
\hline Never & 58.3 & 55.5 & -2.8 \\
\hline Past & 24.8 & 32.1 & 7.3 \\
\hline Current & 17.0 & 12.3 & -4.7 \\
\hline \multicolumn{4}{|l|}{ Chronic diseases, \% } \\
\hline No & 90.6 & 85.2 & -5.4 \\
\hline Yes & 9.4 & 14.8 & 5.4 \\
\hline \multicolumn{4}{|l|}{ Screen-time/ week, \% } \\
\hline $3-4 h$ & 59.4 & 60.2 & 0.8 \\
\hline $5-6 h$ & 21.4 & 15.3 & -6.1 \\
\hline$\geq 7 \mathrm{~h}$ & 19.2 & 24.5 & 5.3 \\
\hline Total daily sleep (hours) & $8.0(1.8)$ & $7.7(1.8)$ & $-0.3(2.1)$ \\
\hline \multicolumn{4}{|l|}{ Alcohol intake (grams/day), \% } \\
\hline Low ( $\leq 12.5$ g/day) & 91.4 & 93.5 & 2.1 \\
\hline High (> 12.5 g/day) & 8.6 & 6.5 & -2.1 \\
\hline \multicolumn{4}{|l|}{ Food groups (servings/ day) } \\
\hline Red meat (servings/day) & $0.9(0.71)$ & $0.5(0.5)$ & $-0.4(0.8)$ \\
\hline Fruits (servings/day) & $4.0(4.3)$ & $4.2(4.6)$ & $0.2(5.5)$ \\
\hline Vegetables (servings/day) & $4.3(3.0)$ & $4.3(5.0)$ & $-0.0(5.6)$ \\
\hline Total dairy (servings/day) & $2.0(1.3)$ & $1.5(0.4)$ & $-0.5(1.3)$ \\
\hline Nuts (servings/day) & $0.3(0.5)$ & $0.4(0.8)$ & $0.1(0.9)$ \\
\hline Yogurt (servings/day) & $0.3(0.5)$ & $0.2(0.3)$ & $-0.1(0.5)$ \\
\hline White bread (servings/day) & $0.4(0.7)$ & $0.2(0.4)$ & $-0.2(0.7)$ \\
\hline Tortillas (servings/day) & $3.0(1.9)$ & $3.0(1.8)$ & $-0.0(1.9)$ \\
\hline Orange juice (servings/day) & $0.4(0.6)$ & $0.3(0.5)$ & $-0.1(0.7)$ \\
\hline
\end{tabular}

Age, soft drink intake, weight, physical activity ( $\mathrm{min} /$ day and METS min/day), total daily sleep and food groups are reported as means and standard deviations. The other variables are reported as column percentages. Soft drink intake considered cola and flavor soft drink. A serving of soft drink represents a bottle of 355 $\mathrm{ml}$. Chronic diseases include cirrhosis, diabetes, cardiovascular diseases, cancer and kidney diseases. Low physical activity category ( $<21.44$ min $/$ day) is equal to $<$ $150 \mathrm{~min} /$ week and high physical activity category ( $\geq 21.44 \mathrm{~min} /$ day) is equal to $\geq 150 \mathrm{~min} /$ week, according with physical activity recommendations of WHO 
Table 2 Association between soft drink intake and body weight change in the health workers cohort study, 2004-2010 ( $N=1268)$

\begin{tabular}{|c|c|c|}
\hline Characteristics & $\begin{array}{l}\text { Model } 1 \\
\beta \text {-coefficient } \\
(95 \% \mathrm{Cl})\end{array}$ & $\begin{array}{l}\text { Model } 2 \\
\beta \text {-coefficient } \\
(95 \% \mathrm{Cl})\end{array}$ \\
\hline Soft drink (servings/day) & $0.03(-0.64,0.70)$ & $-0.02(-0.84,0.79)$ \\
\hline Time (years) & $0.46(0.23,0.68)$ & $0.45(0.22,0.68)$ \\
\hline Soft drink $x$ time & $0.10(0.00,0.19)$ & $0.11(-0.02,0.23)$ \\
\hline \multicolumn{3}{|l|}{ Physical activity } \\
\hline Low (referent) & - & - \\
\hline High & $0.42(-0.19,1.03)$ & $0.34(-0.40,1.08)$ \\
\hline Physical activity $x$ time & $-0.11(-0.23,0.01)$ & $-0.10(-0.24,0.05)$ \\
\hline Soft drink $x$ physical activity & - & $0.18(-0.84,1.20)$ \\
\hline Sex $x$ time & $0.08(-0.03,0.18)$ & $0.07(-0.03,0.18)$ \\
\hline Baseline age $x$ time & $-0.02(-0.02,-0.02)$ & $-0.02(-0.02,-0.02)$ \\
\hline $\begin{array}{l}\text { Soft drink } \times \text { physical } \\
\text { activity } x \text { time }\end{array}$ & - & $-0.03(-0.27,0.21)$ \\
\hline AlC test & $12,149.59$ & $12,153.29$ \\
\hline BIC test & $12,301.39$ & $12,316.77$ \\
\hline
\end{tabular}

Model 1: Individual-level fixed effects model of two-way interaction terms (soft drink and time, physical activity and time, sex and time, and baseline age and time), adjusted for education, chronic diseases, smoking status, TV viewing time per week, total daily sleep, alcohol intake and food groups: red meat, total dairy, fruits, vegetables, nuts, yogurt, white bread, tortillas and orange juice. Model 2: Individuallevel fixed effects model of three-way interaction terms (soft drink, time and physical activity), included two-way interaction terms (soft drink and time, physical activity and time, physical activity and soft drink, sex and time, and baseline age and time) adjusted by the same set of covariates of model 1. Age and sex were centered at the baseline mean in both models. $\mathrm{Cl}$ confidence interval, AIC Akaike information criterion, BIC Bayesian information criterion

results were observed when we used METs min/day (see Table S2, available in the Additional file 2). Analyses stratified by baseline BMI showed similar results (see Table S3 and Table S4, available in Additional file 2).

\section{Discussion}

The first aim was to estimate the association between changes in soft drink intake and weight change in a cohort of Mexican adults, with objective measurements of weight. We found that the soft drink intake was associated with weight gain, with an average of $0.10 \mathrm{~kg} / \mathrm{year} /$ serving. The second aim assessed if the association between soft drink and weight differed by levels of physical activity. The results show that the amount of weight gain associated with soft drink intake was similar in people who engaged in low and high levels of leisure-time physical activity. In other words, leisure-time physical activity did not modify the association of weight gain with soft drink intake in this sample.

Meta-analytical evidence has consistently shown that SSB intake is associated with weight gain in adults, after adjustment for physical activity [1, 19, 20, 34]. However, these studies have been mostly conducted in developed countries and used baseline SSB intake to estimate weight gain, with no consideration for SSB intake changes over follow-up. In this study, a 1-serving increase in daily soft drink intake was associated with an additional $0.10 \mathrm{~kg}$ annual weight gain, after adjustment for leisure-time physical activity and other covariates. The result of this analysis is very similar to the result of the meta-analysis by Malik, et al., which used a similar modeling approach $(0.12 \mathrm{~kg} /$ year, 95\% CI: $0.10,0.14)$ [19]. Nevertheless, this meta-analysis did not include evidence from Hispanic populations. A study conducted in Mexican women found an increase of $1.0 \mathrm{~kg}$ (95\% CI 0.7, 1.2) per soft drink serving over 2 years of follow-up, suggesting a stronger association than estimated by this analysis [15]. This difference could be due to the use of self-reported weight, compared to the objective weight assessment from this study. There are also important differences in the participants of each cohort study; in this case, it is mostly constituted by men and women working in a healthcare public system, while Stern's, et al., is composed of female teachers.

This study also provides further evidence that high levels of physical activity do not modify the weight gain associated with soft drink intake. According to the statistical model, subjects who meet the WHO physical activity guidelines did not reach the amounts of physical activity necessary to counteract the energy consumed from soft drink. In line with these results, a prospective study among adolescents and adults found that vigorous physical activity did not modify the association between sports drinks intake and weight gain [35]. This evidence challenges the idea that the calories burned with leisuretime physical activity can offset the caloric intake of SSB [36-38]. Furthermore, there was no significant difference in the weight gained by each SSB serving, even at high levels of physical activity (PA) (60 min/day). We suggest that the explanation for this observation is related to the complex regulation of calories by solids and liquids. Theoretically, all caloric intake could be offset by engaging in sufficient physical activity [39, 40]. However, liquid calories are known to produce less appetite suppression than solids and lower energy compensation [41-46]. Thus, caloric regulation through appetite is mostly based on solids and not liquids. This could explain the similar weight gain associated with soft drink intake across levels of PA: people should be adjusting their caloric intake based on solids, making every soft drink serving an extra caloric source that is reflected in weight gain. Further experimental studies on the caloric dynamics of SSB intake are needed to better understand their role in weight gain.

According to the statistical model it is implausible to balance weight gain only by increasing physical activity levels at the population-level. Physical activity needs to match the intake of solid food and liquids in a given 


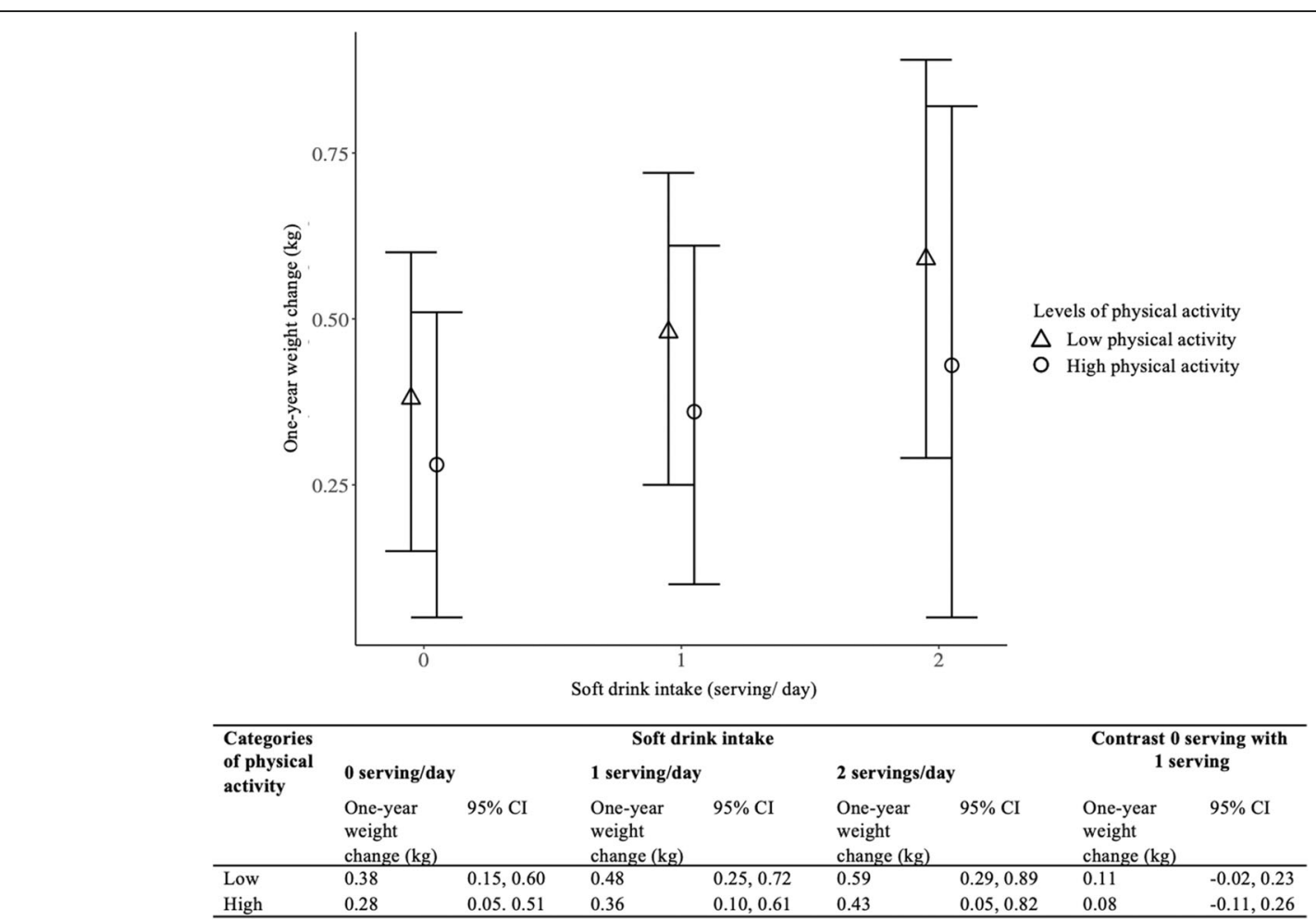

Fig. 1 Annualized body weight change associated with soft drink intake by levels of leisure-time physical activity of three-way interaction model, 2004-2010 HWCS ( $N=1268)$. Cl: Confidence interval

population to achieve energy balance. In modern societies, only a small proportion of the population engages in sufficiently high levels of physical activity to balance out the caloric intake from highly affordable and caloriedense foods [47]. To put the results in context, $72.3 \%$ of the Mexican population complies with the WHO recommendations for physical activity $(75 \mathrm{~min} /$ week of vigorous physical activity or $150 \mathrm{~min} /$ week of moderate physical activity) $[28,48]$. Yet, according to the National Health and Nutrition Survey 2012, the mean caloric intake from soda was $207 \mathrm{kcal} /$ day among adults aged $\geq 20$ years old, equivalent to drinking 1.4 servings of soft drink/day. To offset this caloric intake, without taking into consideration other caloric sources, an average 70 $\mathrm{kg}$ adult would need to perform $588 \mathrm{~min} /$ week of vigorous physical activity (WHO recommends $210 \mathrm{~min} /$ week) or $662 \mathrm{~min} /$ week of moderate physical activity (WHO recommends $315 \mathrm{~min} /$ week) [49]. While some individuals may be healthy and able to reach the aforementioned physical activity level, achieving population weight control only through physical activity was implausible in the individuals of the sample. Physical activity is an integral part of a healthy lifestyle, and plenty of evidence supports its promotion to provide health benefits for weight gain [50]. However, diet is the major contributor of weight gain at the population level. In fact, the Mexican diet is increasingly comprised of ultra- processed foods, which has been shown to be highly palatable and linked with excessive weight gain [51-54].

Some limitations must be considered. Measurement error from self-reported questionnaires such as the FFQ and physical activity needs to be acknowledged. Soft drink intake measured using an FFQ may differ from usual intake, leading to misclassification bias. Yet, for that misclassification bias to explain these findings, we would need for recall to induce higher reporting in people who gained weight and lower reporting amongst people who did not gain weight. Weight trajectories are heavily influenced by baseline values. Thus, to explore this possibility, we stratified the models by baseline weight. Both, people with and without overweight and obesity, showed similar results (see Table S3 and Table S4, available in Additional file 2). This suggests that these findings are not linked to obesity status at baseline or other variables related to it, such as soft drink recall due to obesity or weight gain. Likewise, levels of physical activity can vary according to BMI categories. However, the distribution of low and high levels of leisure-time physical activity was similar in people with obesity, overweight and normal/underweight weight. Overall, the literature suggests, if anything, that overweight people underestimate their caloric intake, particularly on perceived unhealthy foods and beverages [55-58]. This would lead to an underestimate of SSB intake among 
overweight individuals and lead to a larger physical activity effect. This cohort study is relatively small, which could limit the ability to detect statistical significance of the three-way interaction. Yet, the coefficient of the triple interaction was near zero, with both positive and negative effects being equally likely. Thus, it is implausible that increasing the sample size would lead to a clinically relevant effect modification of leisure-time physical activity in the association between soft drink and weight gain. Given the observational nature of this study, we cannot rule out the possibility of residual confounding. Finally, this cohort is not a representative sample of Mexican adults due to different prevalence of chronic diseases with the general population level. Despite these potential limitations, the study has several strengths. We used a prospective study design to analyze a direct path between soft drink intake and weight change. We used objective measurements for weight. We also used an analytical approach that controls for time-invariant confounders, whether they were measured or not. Additionally, the statistical models were controlled by covariates of food groups linked with soft drink intake and weight change. The results were robust for the different sensitivity analyses. Sociodemographic characteristics were similar between the analytic and the full sample, yet, out analytical sample had slightly less women and more participants with secondary and high-school education (see Table S5, available in Additional file 2). Finally, these results can be generalized to other regions where the average soft drink intake is similar to the one of the HWCS population if the modifiers of the association are distributed equally.

\section{Conclusion}

In a cohort of Mexican adults, we found that soft drink intake was associated with weight gain. We failed to observe a modifying effect of physical activity over the soft drink intake and weight association; physical activity levels would need to be much higher than observed in this cohort to counterbalance excess energy intake. Public health policies should focus on the regulation of SSB intake at population level, beyond promoting physical activity.

\section{Supplementary information}

Supplementary information accompanies this paper at https://doi.org/10. 1186/s12966-020-00963-2.

Additional file 1: Figure S1. Directed Acyclic Graph (DAG) of the association of soft drink intake and weight change, with the effect modification by physical activity. Figure about the association between soft drink intake, body weight, and physical activity. Figure S2. Participants flow diagram of the Health Workers Cohort Study, 20042010. Figure containing the flowchart of the exclusion criteria of the sample from the Health Workers Cohort Study. Statistical models. File explaining the statistical models used in the analysis.

Additional file 2: Table S1. Association between soft drink intake and body weight change using physical activity in minutes per day (continuous variable), in the Health Workers Cohort Study, 2004-2010 $(N=1268)$. Table containing the results of the fixed effect model with a three-way interaction term between soft drink, time, and leisure-time physical activity in minutes per day (continuous variable). Figure S3. Annualized body weight change associated with soft drink intake by levels of leisure-time physical activity (continuous variable) of three-way interaction model, 2004-2010 HWCS ( $N=1268)$. Figure containing the predicted average marginal weight change estimates from fixed effect model with a three-way interaction term between soft drink, time, and leisure-time physical activity in minutes per day (continuous variable). Table S2. Association between soft drink intake and body weight change using metabolic equivalent units (METS) minutes per day, in the Health Workers Cohort Study, 2004-2010 ( $N=1268)$. Table containing the results of the fixed effect model with a three-way interaction term between soft drink, time, and leisure-time physical activity in METS min/day (categorical variable). Table S3. Annualized body weight change associated with soft drink intake by levels of leisure-time physical, in people with BMI $<25 \mathrm{~kg} / \mathrm{m}^{2}, 2004-2010$ HWCS $(N=506)$. Table containing the predicted average marginal weight change estimates from fixed effect model with a three-way interaction term between soft drink, time, and leisure-time physical activity, in people with BMI $<25 \mathrm{~kg} / \mathrm{m}^{2}$. Table S4. Annualized body weight change associated with soft drink intake by levels of leisure-time physical, in people with BMI $\geq 25 \mathrm{~kg} / \mathrm{m}^{2}, 2004-2010$ HWCS $(N=762)$. Table containing the predicted average marginal weight change estimates from fixed effect model with a three-way interaction term between soft drink, time, and leisure-time physical activity, in people with BMI $\geq 25 \mathrm{~kg} / \mathrm{m}^{2}$. Table S5. Sociodemographic characteristics in full and analytic samples for 2004. Table containing differences in the sociodemographic characteristics between full sample and analytical sample at baseline.

\section{Abbreviations}

WHO: World Health Organization; SSB: Sugar sweetened beverages; HWCS: Health workers cohort study; FFQ: Food frequency questionnaire; AIC: Akaike Information Criterion; BIC: Bayesian Information Criterion; METs: Minutes of Metabolic Equivalent units

\section{Acknowledgements}

We are extremely grateful to the Health Workers Cohort Study participants, as, without their participation, this study would not have been possible. We thank Rossana Álvarez-Torres for her valuable help with the graphics.

\section{Authors' contributions}

Conceptualization and design of the research: TBG RGM FCO DS LMSR LTI RHL BRP JS. Data curation: PRP RGM. Formal analysis: RGM FCO DS TBG. Writing - original draft: RGM FCO DS LMSR LTI RHL BRP DVP. Writing review \& editing: DS TBG JS BP. All authors read and approved the final manuscript.

\section{Funding}

This work was supported by Bloomberg Philanthropies and NIH R01DK108148.

\section{Availability of data and materials}

The cohort data supporting the conclusions of this article are not publicly available. The material supporting the conclusions of this article are included in additional files.

\section{Ethics approval and consent to participate}

The study protocol, questionnaires, procedures, and informed consent forms were approved by the corresponding IRBs of all participating institutions: the Mexican Social Security Institute (12CEI 09006 14), the National Institute of Public Health (13CEI 17007 36), and the Autonomous University of the State of Mexico (1233008X0236). All participants signed an informed consent to enroll in the study. 


\section{Consent for publication}

Not applicable.

\section{Competing interests}

The authors declare that they have no competing interests.

\section{Author details}

'Center for Population Health Research, National Institute of Public Health, 62100 Cuernavaca, Mor., Mexico. ${ }^{2}$ CONACyT- Center for Population Health Research, National Institute of Public Health, Cuernavaca, Mor., Mexico. ${ }^{3}$ Center for Research in Policies, Population and Health, Faculty of Medicine, National Autonomous University of Mexico, Mexico city, Mexico.

${ }^{4}$ Epidemiological Research and Health Services Unit, Mexican Institute of Social Security, Cuernavaca, Mor., Mexico. ${ }^{5}$ Department of Nutrition, Gillings School of Global Public Health, University of North Carolina at Chapel Hill, Chapel Hill, North Carolina, USA.

Received: 29 November 2019 Accepted: 28 April 2020 Published online: 12 May 2020

\section{References}

1. Ruanpeng D, Thongprayoon C, Cheungpasitporn W, Harindhanavudhi T. Sugar and artificially sweetened beverages linked to obesity: a systematic review and meta-analysis. QJM. 2017;110:513-20 [cited 2019 Sep 23]; Available from: https://academic.oup.com/qimed/article-abstract/110/ 8/513/3574201.

2. Dhingra $R$, Sullivan $L$, Jacques PF, Wang TJ, Fox CS, Meigs JB, et al. Soft drink consumption and risk of developing cardiometabolic risk factors and the metabolic syndrome in middle-aged adults in the community. Circulation. 2007;116:480-8

3. Malik VS, Pan A, Willett WC, Hu FB. Sugar-sweetened beverages and weight gain in children and adults: a systematic review and meta-analysis. Am J Clin Nutr. 2013;98:1084-102 [cited 2018 may 18] Available from: http:// www.ncbi.n/m.nih.gov/pubmed/23966427.

4. Appelhans BM, Bleil ME, Waring ME, Schneider KL, Nackers LM, Busch AM, et al. Beverages contribute extra calories to meals and daily energy intake in overweight and obese women. Physiol Behav. 2013;122:129-33 NIH Public Access; [cited 2019 Aug 8] Available from: http://www.ncbi.nlm.nih.gov/ pubmed/24041722.

5. Mathias KC, Slining MM, Popkin BM. Foods and Beverages Associated with Higher Intake of Sugar-Sweetened Beverages. Am J Prev Med. 2013;44:3517 [cited 2019 Oct 4]. Available from: http://www.ncbi.nlm.nih.gov/ pubmed/23498100.

6. Ferretti F, Mariani M. Sugar-sweetened beverage affordability and the prevalence of overweight and obesity in a cross section of countries. Global Health. 2019;15:30.

7. National Institute of Statistic and Geography, National Institute of Public Health, Secretariat of Health. National Health and Nutrition Survey. Presentation of results 2019. 2018.

8. Hu FB, Malik VS. Sugar-sweetened beverages and risk of obesity and type 2 diabetes: epidemiologic evidence. Physiol Behav. 2010;100:47-54 [cited 2017 Oct 11]. NIH Public Access; Available from: http://www.ncbi.nlm.nih. gov/pubmed/20138901.

9. Bes-Rastrollo M, Sánchez-Villegas A, Gómez-Gracia E, Martínez JA, Pajares RM, Martínez-González MA. Predictors of weight gain in a Mediterranean cohort: the Seguimiento Universidad de Navarra study. Am J Clin Nutr. 2006:83:362-70.

10. Lim L, Banwell C, Bain C, Banks E, Seubsman SA, Kelly M, et al. Sugar sweetened beverages and weight gain over 4 years in a Thai national cohort - a prospective analysis. PLoS One. 2014;9:e95309.

11. Odegaard AO, Koh WP, Arakawa K, Yu MC, Pereira MA. Soft drink and juice consumption and risk of physician-diagnosed incident type 2 diabetes: the Singapore Chinese health study. Am J Epidemiol. 2010;171:701-8.

12. Smith JD, Hou T, Hu FB, Rimm EB, Spiegelman D, Willett WC, et al. A comparison of different methods for evaluating diet, physical activity, and long-term weight gain in 3 prospective cohort studies. J Nutr. 2015;145: 2527-34 American Society for Nutrition; [cited 2019 Oct 2]. Available from: http://www.ncbi.nlm.nih.gov/pubmed/26377763.

13. Singer JD, Willet JB. Applied longitudinal data analysis: modeling change and event occurrence; 2003.
14. Basto-Abreu A, Braverman-Bronstein A, Camacho-García-Formentí D, Zepeda-Tello R, Popkin BM, Rivera-Dommarco J, et al. Expected changes in obesity after reformulation to reduce added sugars in beverages: a modeling study. PLoS Med. 2018;15:e1002664.

15. Stern D, Middaugh N, Rice MS, Laden F, López-Ridaura R, Rosner B, et al. Changes in Sugar-Sweetened Soda Consumption, Weight, and Waist Circumference: 2-Year Cohort of Mexican Women. Am J Public Health. 2017; 107:1801-8 American Public Health Association; [cited 2017 Nov 14]. Available from: http://www.ncbi.nlm.nih.gov/pubmed/28933937.

16. Pan A, Malik VS, Hao T, Willett WC, Mozaffarian D, Hu FB. Changes in water and beverage intake and long-term weight changes: results from three prospective cohort studies. Int J Obes (Lond). 2013;37:1378-85 NIH Public Access; [cited 2017 Oct 17]. Available from: http://www.ncbi.nlm.nih.gov/ pubmed/23318721.

17. Barone Gibbs B, Kinzel LS, Pettee Gabriel K, Chang Y-F, Kuller LH. Short- and long-term eating habit modification predicts weight change in overweight, postmenopausal women: results from the WOMAN study. J Acad Nutr diet. 2012;112:1347-1355.e2 [cited 2019 Oct 9]. NIH Public access; Available from: http://www.ncbi.nlm.nih.gov/pubmed/22939439.

18. Mozaffarian D, Hao T, Rimm EB, Willett WC, Hu FB. Changes in diet and lifestyle and long-term weight gain in women and men. N Engl J Med. 2011;364:2392-404 NIH Public Access; [cited 2018 may 18]. Available from: http://www.ncbi.nlm.nih.gov/pubmed/21696306.

19. Malik VS, Pan A, Willett WC, Hu FB. Sugar-sweetened beverages and weight gain in children and adults: a systematic review and meta-analysis. Am J Clin Nutr. 2013;98:1084-102 American Society for Nutrition; [cited 2017 Oct 31]. Available from: http://www.ncbi.nlm.nih.gov/pubmed/23966427.

20. Luger M, Lafontan M, Bes-Rastrollo M, Winzer E, Yumuk V, Farpour-Lambert N. Sugar-sweetened beverages and weight gain in children and adults: a systematic review from 2013 to 2015 and a comparison with previous studies. Obes Facts. 2017;10:674-93 [cited 2019 Sep 16]. Available from: http://www.ncbi.nlm.nih.gov/pubmed/29237159.

21. Cook CM, Schoeller DA. Physical activity and weight control: conflicting findings. Curr Opin Clin Nutr Metab Care. 2011;14:419-24 [cited 2018 Apr 9]. Available from: https://insights.ovid.com/crossref?an=00075197-201109000-00003.

22. Serôdio PM, McKee M, Stuckler D. Coca-Cola - a model of transparency in research partnerships? A network analysis of Coca-Cola's research funding (2008-2016). Public Health Nutr. 2018:1-14 [cited 2018 Apr 9]. Cambridge University Press; Available from: https://www.cambridge.org/core/product/ identifier/S136898001700307X/type/journal_article.

23. Denova-Gutiérrez E, Ramírez-Silva I, Rodríguez-Ramírez S, Jiménez-Aguilar A, Shamah-Levy T, Rivera-Dommarco JA. Validity of a food frequency questionnaire to assess food intake in Mexican adolescent and adult population. Salud Publica Mex. 2016;58:617 Available from: http://www. saludpublica.mx/index.php/spm/article/view/7862.

24. Hernández-Avila M, Romieu I, Parra S, Hernández-Avila J, Madrigal H, Willet W. Validity and reproducibility of a food frequency questionnaire to assess dietary intake of women living in Mexico City. Salud Publica Mex. 1998;40: 133-40 [cited 2017 Aug 23]. Available from: http://www.scielosp.org/pdf/ spm/v40n2/Y0400205.pdf.

25. Garrow JS, Webster J. Quetelet's index (W/H2) as a measure of fatness. Int J Obes. 1985;9:147-53.

26. Denova-Gutiérrez E, Flores YN, Gallegos-Carrillo K, Ramírez-Palacios P, RiveraParedez B, Muñoz-Aguirre P, et al. Health workers cohort study: methods and study design. Salud Publica Mex. 2016;58:708-16.

27. Martínez-González MA, López-Fontana C, Varo JJ, Sánchez-Villegas A, Martinez JA. Validation of the spanish version of the physical activity questionnaire used in the nurses' health study and the health professionals' follow-up study. Public Health Nutr. 2005;8:920-7 [cited 2018 Sep 24]. Available from: http://www.ncbi.nlm.nih.gov/pubmed/16277809.

28. World Health Organization. Global recommendations on physical activity for health. 2010. Available from: http://apps.who.int/iris/bitstream/handle/1 0665/44399/9789241599979_eng.pdf?sequence=1.

29. Morrell CH, Brant LJ, Ferrucci L. Model choice can obscure results in longitudinal studies. J Gerontol A Biol Sci Med Sci. 2009;64:215-22 Oxford University Press; [cited 2018 Aug 13]. Available from: http://www.ncbi.nlm. nih.gov/pubmed/19196902.

30. World Health Organization. Tobacco or health: a global status report; 1997. p. 495. Available from: http://apps.who.int//iris/handle/10665/41922.

31. Tremblay MS, Aubert S, Barnes JD, Saunders TJ, Carson V, Latimer-Cheung $A E$, et al. Sedentary Behavior Research Network (SBRN) - Terminology 
Consensus Project process and outcome. Int J Behav Nutr Phys Act. 2017;14: -75 BioMed Central; [cited 2018 Apr 10]. Available from: http://www.ncbi. nlm.nih.gov/pubmed/28599680.

32. Bagnardi V, Randi G, Lubin J, Consonni D, Lam TK, Subar AF, et al. Alcohol consumption and lung cancer risk in the Environment and Genetics in Lung Cancer Etiology (EAGLE) study. Am J Epidemiol. 2010;171:36-44 Oxford University Press; [cited 2018 Jun 13]. Available from: http://www. ncbi.nlm.nih.gov/pubmed/19933698.

33. Data Analysis and Statistical Software | Stata. [cited 2017 Nov 27]. Available from: https://www.stata.com/

34. Schlesinger S, Neuenschwander M, Schwedhelm C, Hoffmann G, Bechthold A, Boeing $\mathrm{H}$, et al. Food Groups and Risk of Overweight, Obesity, and Weight Gain: A Systematic Review and Dose-Response Meta-Analysis of Prospective Studies. Adv Nutr. 2019;10:205-18. [cited 2019 Sep 23]. https:// doi.org/10.1093/advances/nmy092.

35. Field AE, Sonneville KR, Falbe J, Flint A, Haines J, Rosner B, et al. Association of sports drinks with weight gain among adolescents and young adults. Obesity. 2014;22:2238-43 NIH Public Access. [cited 2019 Sep 16]Available from: http://www.ncbi.nlm.nih.gov/pubmed/25044989.

36. Barlow P, Serôdio P, Ruskin G, Mckee M, Stuckler D. Science organisations and Coca-Cola's "war" with the public health community: insights from an internal industry document. J Epidemiol Community Health. 2018;72:761-3 BMJ Publishing Group Ltd; [cited 2018 Apr 9]. Available from: http://www. ncbi.nlm.nih.gov/pubmed/29540465.

37. Campbell J. You don't need to do "one iota" of exercise to lose weight, says scientific study | The Independent. 2015 [cited 2018 Mar 26]. Available from: https:/www.independent.co.uk/life-style/health-and-families/you-dontneed-to-do-one-iota-of-exercise-to-lose-weight-says-scientific-study-101 97434.html.

38. Olson S. Coca-cola pays scientists to blame obesity epidemic on lack of physical activity: what the real cause is, according to experts. 2015 [cited 2018 Apr 2]. Available from: http://www.medicaldaily.com/coca-cola-paysscientists-blame-obesity-epidemic-lack-physical-activity-what-real-347026.

39. Hill JO, Wyatt HR, Peters JC. Energy balance and obesity. Circulation. 2012. 126:126-32 NIH Public Access; [cited 2018 may 18]. Available from: http:// www.ncbi.nlm.nih.gov/pubmed/22753534

40. Romieu I, Dossus L, Barquera S, Blottière HM, Franks PW, Gunter M, et al. Energy balance and obesity: what are the main drivers? Cancer Causes Control. 2017;28:247-58 Springer; [cited 2018 may 18]. Available from: http://www.ncbi.nlm.nih.gov/pubmed/28210884.

41. Allison DB. Liquid calories, energy compensation and weight: what we know and what we still need to learn. Br J Nutr. 2014;11:384-6 NIH Public Access; [cited 2019 Aug 8]. Available from: http://www.ncbi.nlm.nih.gov/ pubmed/24164833.

42. Maersk M, Belza A, Holst JJ, Fenger-Grøn M, Pedersen SB, Astrup A, et al. Satiety scores and satiety hormone response after sucrose-sweetened soft drink compared with isocaloric semi-skimmed milk and with non-caloric soft drink: a controlled trial. Eur J Clin Nutr. 2012;66:523-9 [cited 2019 Aug 8]. Available from: www.nature.com/ejcn.

43. Reid M, Hammersley R, Duffy M, Ballantyne C. Effects on obese women of the sugar sucrose added to the diet over $28 \mathrm{~d}$ : a quasi-randomised, singleblind, controlled trial. Br J Nutr. 2014;111:563-70 Cambridge University Press; [cited 2019 Aug 8]. Available from: http://www.ncbi.nlm.nih.gov/ pubmed/24164779.

44. DiMeglio D, Mattes R. Liquid versus solid carbohydrate: effects on food intake and body weight. Int J Obes. 2000;24:794-800 Nature Publishing Group; [cited 2019 Aug 8]. Available from: http://www.nature.com/articles/ 0801229.

45. Dellavalle DM, Roe LS, Rolls BJ. Does the consumption of caloric and noncaloric beverages with a meal affect energy intake? Appetite. 2005;44:187-93.

46. Mourao DM, Bressan J, Campbell WW, Mattes RD. Effects of food form on appetite and energy intake in lean and obese young adults. Int J Obes. 2007;31:1688-95.

47. Ng SW, Popkin B. Time use and physical activity: a shift away from movement across the globe. Obes Rev. 2012;13:659-80 [cited 2019 Jun 24]. NIH Public Access; Available from: http://www.ncbi.nlm.nih.gov/ pubmed/22694051.

48. Medina C, Barquera S, Janssen I. Resultados de actividad física y sedentarismo en personas de 10 a 69 años. Available from: https://ensanut. insp.mx/doctos/analiticos/ActividadFisica.pdf.
49. Ainsworth BE, Haskell WL, Herrmann SD, Meckes N, Bassett DR, Tudor-locke C, et al. 2011 Compendium of Physical Activities: A Second Update of Codes and Met Values. Med Sci Sports Exerc. 2011;43:1575-81 [cited 2018 May 18]. Available from: https://insights.ovid.com/pubmed?pmid=21681120.

50. Warburton DER, Bredin SSD. Health benefits of physical activity: a systematic review of current systematic reviews. Curr Opin Cardiol. 2017;32:541-56.

51. Popkin BM. Nutrition, agriculture and the global food system in low and middle income countries. Food Policy. 2014;47:91-6.

52. Marrón-Ponce JA, Sánchez-Pimienta TG, Da Costa Louzada ML, Batis C. Energy contribution of NOVA food groups and sociodemographic determinants of ultra-processed food consumption in the Mexican population. Public Health Nutr. 2018;21:87-93.

53. Popkin BM, Reardon T. Obesity and the food system transformation in Latin America. Obes Rev. 2018;19:1028-64 Blackwell Publishing Ltd.

54. Hall KD, Ayuketah A, Brychta R, Walter PJ, Yang S, Zhou M. Clinical and Translational Report ultra-processed diets cause excess calorie intake and weight gain: an inpatient randomized controlled trial of ad libitum food intake. Cell Metab 2019;30:67-77. [cited 2019 Nov 13]. https://doi.org/10. 1016/j.cmet.2019.05.008.

55. Lafay L, Basdevant A, Charles M-A, Vray M, Balkau B, Borys J-M, et al. Determinants and nature of dietary underreporting in a free-living population: the Fleurbaix Laventie Ville Santé (FLVS) study. Int J Obes. 1997; 21:567-73 [cited 2019 Nov 13]. Available from: http://www.nature.com/ articles/0800443.

56. Kipnis V, Midthune D, Freedman L, Bingham S, Day NE, Riboli E, et al. Bias in dietary-report instruments and its implications for nutritional epidemiology. Public Health Nutr. 2002;5:915-23 [cited 2019 Nov 13]. Available from: http://www.ncbi.nlm.nih.gov/pubmed/12633516.

57. Drapeau V, Després JP, Bouchard C, Allard L, Fournier G, Leblanc C, et al. Modifications in food-group consumption are related to long-term bodyweight changes. Am J Clin Nutr. 2004;80:29-37.

58. Hebert JR, Hurley TG, Peterson KE, Resnicow K, Thompson FE, Yaroch AL, et al. Social desirability trait influences on self-reported dietary measures among diverse participants in a multicenter multiple risk factor trial. J Nutr. 2008:138:226S-34S [cited 2019 Nov 13]. Available from: http://www.ncbi. nlm.nih.gov/pubmed/18156429.

\section{Publisher's Note}

Springer Nature remains neutral with regard to jurisdictional claims in published maps and institutional affiliations.

Ready to submit your research? Choose BMC and benefit from:

- fast, convenient online submission

- thorough peer review by experienced researchers in your field

- rapid publication on acceptance

- support for research data, including large and complex data types

- gold Open Access which fosters wider collaboration and increased citations

- maximum visibility for your research: over $100 \mathrm{M}$ website views per year

At BMC, research is always in progress.

Learn more biomedcentral.com/submissions 